\title{
Etat et communautarisme en Bosnie-Herzegovine
}

\section{Xavier Bougarel}

\section{OpenEdition}

1 Journals

\section{Édition électronique}

URL : http://journals.openedition.org/conflits/199

DOI : 10.4000/conflits.199

ISSN : 1777-5345

Éditeur :

CCLS - Centre d'études sur les conflits lilberté et sécurité, L'Harmattan

Édition imprimée

Date de publication : 15 octobre 1994

ISSN : 1157-996X

Référence électronique

Xavier Bougarel, «Etat et communautarisme en Bosnie-Herzegovine », Cultures \& Conflits [En ligne], 15-16 | automne-hiver 1994, mis en ligne le 15 mars 2006, consulté le 30 mars 2021. URL : http:// journals.openedition.org/conflits/199; DOI : https://doi.org/10.4000/conflits.199

Ce document a été généré automatiquement le 30 mars 2021.

Creative Commons License 


\title{
Etat et communautarisme en Bosnie-Herzegovine
}

\author{
Xavier Bougarel
}

1 L'éclatement de la guerre en Bosnie-Herzégovine en avril 1992 s'est immédiatement accompagné de polémiques sur la nature de cette guerre et, au-delà, de la société bosniaque. A ceux qui invoquent «cinq cents ans de tolérance et de démocratie» répondent ceux qui, reprenant le propos d'Ivo Andric, évoquent « un pays de haine et de peur ${ }^{1}$. Carrefour des civilisations, la Bosnie-Herzégovine est bel et bien une terre de rencontre, de coexistence et, parfois, de symbiose. Périphérie des Empires, elle est aussi une terre où, avec une récurrence presque surprenante, les guerres des autres viennent nourrir et se nourrir des conflits propres à la société bosniaque. De ce point de vue, les mots de "tolérance» et de "haine», de «coexistence » et de "peur " peuvent également servir à qualifier la société bosniaque : en son sein, ils se complètent ou se succèdent plus qu'ils ne s'opposent. S'il est, par contre, un mot qui peut difficilement qualifier la société bosniaque et son histoire, c'est celui de « démocratie ». D'une part, les ordres politiques qui se sont succédés en Bosnie-Herzégovine, de l'Empire ottoman (1463-1878) au communisme yougoslave (1945-1990), ne sont pas de nature démocratique. Seuls la fin de l'occupation austro-hongroise (1878-1918) et le début de la monarchie yougoslave (1918-1941) ont connu un semblant de vie parlementaire. D'autre part, le concept de démocratie sous-entend généralement celui de citoyenneté. Or, le principe structurant de l'ordre politique bosniaque n'est pas la citoyenneté mais l'appartenance communautaire : de 1910 à 1990, toutes les élections tenues en Bosnie-Herzégovine se sont soldées par une large domination des partis nationaux. Cela ne signifie certes pas que le communautarisme soit, en BosnieHerzégovine, immuable ou incontesté, ni que la vague d'aspirations démocratiques et citoyennes caractéristique de l'Europe centrale et orientale des années 1980 ait contourné cette république de l'ex-Yougoslavie. Cela signifie, en tout cas, que la crise actuelle ne peut être comprise sans tenir compte de cette dimension essentielle de la réalité bosniaque, masquée par les uns et défigurée par les autres. 
Des Millets aux Nations : la rigidification des communautés Dans les premiers siècles de la période ottomane, l'islamisation d'une grande partie de la population bosniaque, l'installation d'importantes populations orthodoxes et de populations juives plus réduites donnent à la Bosnie-Herzégovine ses caractéristiques confessionnelles contemporaines ${ }^{2}$. Mais les statuts sociaux ne coïncident pas encore pleinement avec les appartenances confessionnelles: les chrétiens continuent d'occuper une place importante au sein des élites militaires et féodales bosniaques, alors que les rayas (sujets, producteurs) musulmans et chrétiens partagent un sort semblable. Ces premiers siècles sont d'ailleurs marqués par une grande fluidité des appartenances confessionnelles, et par d'importantes jacqueries opposant des paysans musulmans à leurs féodaux également musulmans. A partir du milieu du XVIIIe siècle, la lente sclérose de l'Empire ottoman s'accompagne pourtant d'une rigidification des frontières communautaires ${ }^{3}$. L'organisation des populations chrétiennes en millets (communauté religieuse bénéficiant d'une large autonomie interne) attribue à leurs églises un rôle social et culturel essentiel, mais n'empêche pas la détérioration de leur statut économique. Cette évolution est particulièrement sensible en Bosnie-Herzégovine, frontière de l'Empire ottoman, où les élites musulmanes locales monopolisent le pouvoir à leur profit, et où les populations chrétiennes sont perçues comme alliées potentielles de l'Empire austro-hongrois. La société bosniaque apparaît alors structurée par les appartenances communautaires: les millets déterminent non seulement un certain nombre de questions d'ordre juridique (régimes fiscaux et juridictions propres à chaque millet), mais correspondent aussi, dans les villes, à certains quartiers et à certaines corporations. Dans les campagnes, ils recoupent largement des oppositions socio-économiques. En 1910, plus de trente ans après la fin de la présence ottomane en Bosnie-Herzégovine, $91,1 \%$ des propriétaires terriens ayant des kmets (serfs) à leur service sont musulmans, $95,4 \%$ des kmets sont orthodoxes ou catholiques. A la fluidité des appartenances et des rapports confessionnels succède donc une fermeture croissante des communautés. Le komsiluk (bon voisinage) est certes la règle dans les rapports quotidiens entre communautés, mais il repose sur une réaffirmation constante des appartenances et des codes communautaires, et non sur leur effacement. Le komsiluk ne devient jamais intimité. Par les rapports qu'il institue entre sphère publique et sphère privée, entre appartenance communautaire et lien social, il représente l'inverse de la citoyenneté plutôt que son prémisse. Le rapport entre millets et modernité politique, symbolisée au XIXe siècle par le nationalisme, est sans doute plus ambigu ${ }^{4}$. L'institutionnalisation tardive des millets s'insère dans les efforts de modernisation et de réforme entrepris au XIXe siècle par l'Etat ottoman. Toutefois, alors que les mouvements nationalistes d'Europe orientale placent l'Etat au centre de l'ordre politique, les mobilisations communautaires que connaît la Bosnie-Herzégovine à la même époque cherchent à le tenir à distance. L'insurrection des féodaux musulmans contre les réformes ottomanes en 1831 comme celle des paysans serbes d'Herzégovine contre l'impôt en 1875 s'opposent en fait au renforcement du rôle de l'Etat. La première ne constitue en aucun cas un mouvement nationaliste, la seconde ne le devient qu'après l'intervention du jeune Etat serbe voisin et l'internationalisation de cette première crise bosniaque. La constitution d'un appareil d'Etat moderne en BosnieHerzégovine, suite à l'occupation austro-hongroise de 1878, constitue donc une rupture essentielle. Cette modernisation politique et les débuts de la modernisation économique et culturelle expliquent la lente transformation des identités et des rapports communautaires hérités de la période ottomane ${ }^{5}$. Dans un premier temps, 
l'Empire austro-hongrois, soucieux de contrecarrer l'influence des nationalismes serbe et croate, tente de promouvoir une identité bosniaque globalisante, prenant le contrôle des structures religieuses de Bosnie-Herzégovine (nomination par l'Empereur des évêques catholiques et orthodoxes, et d'un Reis-ul-Ulema pour les musulmans) et interdisant même l'emploi des termes «serbe» et "croate» dans l'intitulé des associations culturelles. Cette politique volontariste trouve un soutien auprès d'élites musulmanes modernes naissantes, mais se heurte à l'hostilité des élites orthodoxes (serbes) et catholiques (croates), ainsi qu'à celle des élites musulmanes traditionnelles. Portés par des élites commerçantes ou administratives en plein essor, les nationalismes serbe et croate progressent rapidement dans les communautés orthodoxe et catholique de Bosnie-Herzégovine. La communauté musulmane, elle, se mobilise autour de ses élites religieuses et terriennes, et autour de la revendication d'autonomie culturelle et religieuse, sorte de millet inversé au profit de la population musulmane. L'Empire austro-hongrois est dès lors amené à reprendre, puis à favoriser la structuration communautaire de la vie sociale et politique en Bosnie-Herzégovine. Sur le plan économique, il privilégie les élites catholiques (locales ou venues du reste de l'Empire) dans l'administration, et préserve les privilèges agraires des élites musulmanes en échange de leur loyalisme. Sur le plan politique, il accorde une autonomie culturelle et religieuse aux communautés serbe (1903) et musulmane (1909), comprenant, dans ce dernier cas, une désignation du Reis-ul-Ulema par voie électorale (et sa confirmation par le Sheikh-ul-Islam d'Istambul), une administration autonome des waqfs (biens de main-morte) et le maintien des tribunaux shériatiques pour les questions de statut personnel. Un ans plus tard, une Constitution provinciale institue un parlement bosniaque, élu au suffrage censitaire et constitué de "curies» distinctes (37 députés orthodoxes, 29 musulmans, 23 catholiques et un juif). En Bosnie-Herzégovine, l'introduction $\mathrm{du}$ parlementarisme va de pair avec l'institutionnalisation du communautarisme. Pendant la période austro-hongroise, la vie économique, sociale, culturelle et même sportive reste ainsi structurée sur un mode communautaire. Il en va de même pour la vie politique. Les partis nationaux, Muslimanska Narodna Organizacija -MNO (Organisation Populaire Musulmane), Srpska Narodna Organizacija -SNO(Organisation Populaire Serbe) et Hrvatsko Narodno Drustvo -HND (Société Populaire Croate), apparus entre 1905 et 1910, remportent les premières élections parlementaires. Cette période voit donc les débuts d'une vie politique bosniaque caractérisée par les coalitions d'intérêt entre élites politiques des différentes communautés (coalition serbo-musulmane sur la question de l'autonomie culturelle et religieuse jusqu'en 1909, coalition croato-musulmane sur la question de la réforme agraire à partir de 1911), le rôle intermédiaire et pendulaire de la communauté musulmane dans la rivalité serbo-croate naissante, l'appel tactique des communautés à l'Etat et l'instrumentalisation des conflits communautaires par ce même Etat. La première guerre mondiale, partie de Sarajevo, bouleverse les équilibres géopolitiques des Balkans et ébranle une première fois les rapports entre communautés en BosnieHerzégovine (violences contre les populations serbes en 1914, contre les populations musulmanes en 1918). Pourtant, si l'intégration de la Bosnie-Herzégovine dans le Royaume des Serbes, des Croates et des Slovènes - qui deviendra Royaume de Yougoslavie en 1929- modifie radicalement les équilibres économiques et politiques entre communautés (réforme agraire et prise de contrôle de l'appareil d'Etat par les Serbes), elle ne remet pas immédiatement en cause le communautarisme hérité de la période austro-hongroise. Lors des élections de 1920 pour l'Assemblée constituante, le 
vote de la population bosniaque -et yougoslave en général- reste communautaire. Sur 63 députés élus en Bosnie-Herzégovine, seuls les quatre députés communistes peuvent être considérés comme n'appartenant pas à un parti explicitement ou implicitement communautaire. Alors que les communautés serbe et croate sont représentées par plusieurs partis, correspondant à différents courants de leurs nationalismes respectifs ${ }^{6}$, la communauté musulmane est représentée par la seule Jugoslovenska Muslimanska Organizacija (JMO, Organisation Musulmane Yougoslave). Les députés de la JMO, souvent issus de la MNO, reproduisent les stratégies politiques élaborées dans la période austro-hongroise. En mars 1921, ils acceptent de voter une Constitution centralisatrice et de participer au gouvernement, en échange de garanties sur le maintien de la Bosnie-Herzégovine comme entité territoriale spécifique, le statut d'autonomie religieuse de 1909 et l'indemnisation des propriétaires terriens, avant de rejoindre l'opposition menée par le Hrvatska Seljacka Stranka (HSS, Parti Paysan Croate) en février $1922^{7}$. A moyen terme pourtant, les évolutions économiques, culturelles et surtout politiques du Royaume de Yougoslavie conduisent à une grave crise du communautarisme en Bosnie-Herzégovine. Les populations serbe et croate de Bosnie-Herzégovine sont de plus en plus liées à Belgrade et à Zagreb, alors même que le conflit serbo-croate s'envenime rapidement. Dans le même temps, le déclin des élites musulmanes traditionnelles nourrit une profonde crise d'identité de la communauté musulmane. Exposée aux avances et aux pressions croisées des nationalismes serbe et croate, celle-ci se réfugie dans l'« indétermination » nationale et un yougoslavisme tactique. Au fur et à mesure que le conflit serbo-croate se durcit, la marge de manoeuvre politique de la JMO se rétrécit. En 1929, la Bosnie-Herzégovine est partagée en quatre banovinas, l'autonomie des structures religieuses islamiques est supprimée. La JMO accepte pourtant en 1935, contre le rétablissement de cette autonomie, de rentrer au gouvernement. Trois ans plus tard, elle participe à une coalition électorale menée par le parti radical serbe au pouvoir. Pour la première fois, les candidats de la JMO ne recueillent pas la majorité des suffrages musulmans, alors que groupuscules communistes et pan-islamistes se multiplient dans la jeunesse musulmane scolarisée. Lorsqu'en août 1939, le premier ministre serbe D. Cvetkovic et le dirigeant du HSS V. Macek s'accordent sur un partage territorial de la Bosnie-Herzégovine entre la Serbie et un grand banovina de Croatie, la crise d'identité et de représentation de la communauté musulmane atteint son paroxysme. Des responsables de la JMO et des structures religieuses islamiques ${ }^{8}$ constituent un mouvement pour l'autonomie de la Bosnie-Herzégovine. Il éclate à son tour en avril 1941, après l'effondrement de la première Yougoslavie et l'annexion de la Bosnie-Herzégovine par la Croatie indépendante. En Bosnie-Herzégovine éclate alors un conflit d'une rare intensité où résistance à l'occupant et guerre civile, extermination de la population serbe par les oustachis croates et massacres de population musulmane par les tchetniks serbes se mêlent et se répondent. L'effacement du communautarisme institutionnel devant des nationalismes territoriaux et exclusifs se double d'une désagrégation interne de chaque communauté. Ainsi, la communauté musulmane, en pleine crise d'identité et de représentation, voit ses élites dispersées et attentistes, et ses populations organisées tant bien que mal dans une multitude de milices d'auto-défense. La communauté serbe, elle, se retrouve exposée à une politique délibérée de génocide et abandonnée par un mouvement tchetnik dérivant vers le brigandage et la collaboration. Si le mouvement des partisans de Tito parvient alors peu à peu à s'assurer le soutien des populations de Bosnie-Herzégovine, ce n'est pas uniquement parce qu'il leur assure une sécurité 
physique, et encore moins en vertu d'un yougoslavisme ou d'un antifascisme abstrait. L'enracinement progressif du mouvement des partisans s'explique aussi par sa capacité à capter les revendications agraires de la population rurale d'une part, à en reproduire la structuration communautaire d'autre part ${ }^{9}$. De 1941 à 1945, les proclamations du mouvement des partisans en Bosnie-Herzégovine s'adressent invariablement aux "Serbes, Musulmans et Croates ", même si son recrutement est dans un premier temps essentiellement serbe. Tenue le 25 novembre 1943, la première session du Conseil Antifasciste de Libération Populaire de Bosnie-Herzégovine (AVNOBiH) rétablit celle-ci comme entité territoriale spécifique dans laquelle «sera garantie la pleine égalité de tous les Serbes, Musulmans et Croates ". A la même époque, l'entrée massive des Musulmans dans le mouvement des partisans va de pair avec la constitution d'unités spécifiquement musulmanes, au sein desquelles les préceptes, en particulier alimentaires, de la religion islamique sont respectés ${ }^{10}$. Dès 1945, le rapport des communistes yougoslaves au communautarisme est donc pour le moins ambigu ${ }^{11}$. Le Parti Communiste Yougoslave s'attaque aux structures religieuses et communautaires traditionnelles (ainsi, les tribunaux shériatiques et l'association culturelle musulmane Preporod - Renaissance- sont ainsi dissoutes en 1946, les medresas fermées en 1947), moins pour mettre fin à la structuration communautaire elle-même que pour la placer sous son contrôle exclusif. La reconnaissance des nations macédonienne et monténégrine dès 1945, puis de la nation musulmane en 1968, illustre bien ce phénomène. Surtout, par le renouvellement radical des élites économiques et politiques qu'il suscite, le Parti communiste yougoslave s'inscrit dans la continuité des mécanismes constitutifs du communautarisme ${ }^{12}$. Dans l'ensemble de l'espace yougoslave, et en Bosnie-Herzégovine en particulier, les rapports communautaires s'articulent autour de deux enjeux essentiels: le contrôle de l'appareil d'Etat et de la terre. Ces deux enjeux sont, à leur tour, étroitement liés à la question des rapports entre ville et campagne, la ville tendant à dominer économiquement la campagne, et les élites issues de la communauté dominante cherchant donc à s'assurer le contrôle de la ville ${ }^{13}$. Or, depuis 1878 au moins, chaque guerre s'accompagne en Bosnie-Herzégovine d'une modification brutale des rapports de force entre communautés (prise de contrôle de l'appareil d'Etat et redistribution des terres) et de l'éviction des anciennes élites urbaines par de nouvelles élites issues des campagnes. D'où des modifications rapides et erratiques dans la composition ethnique des villes bosniaques, et de Sarajevo en particulier ${ }^{14}$. De ce point de vue, l'accession du Parti communiste yougoslave au pouvoir s'inscrit dans une continuité presque parfaite. Non seulement les terres confisquées aux Allemands en Slavonie et en Voïvodine sont redistribuées à des partisans venus de Bosnie-Herzégovine et du Monténégro, mais les élites économiques et politiques sont profondément renouvelées. Certes, en Bosnie-Herzégovine comme dans toute la Yougoslavie, la communauté serbe reste dans un premier temps surreprésentée dans ces nouvelles élites. Mais les élites serbes de la première Yougoslavie se recrutaient surtout dans la Serbie étroite, et étaient rapidement rentrées en conflit avec les populations rurales serbes de Bosnie-Herzégovine et de Croatie. Celles de la Yougoslavie socialiste, au contraire, sont issues de ces populations serbes périphériques, et évincent les anciennes élites serbes, de Sarajevo jusqu'à Belgrade. La véritable spécificité de la Yougoslavie socialiste est représentée par un projet de modernisation censé conduire à terme à la disparition des particularismes nationaux. Mais la profonde modernisation engagée par la Yougoslavie socialiste, loin de conduire à une fusion révolutionnaire des peuples yougoslaves, conduit en fait à un 
renforcement des identités nationales (voire à leur cristallisation dans les cas macédonien, monténégrin et surtout musulman) puis à une résurgence des pratiques communautaristes et des idéologies nationalistes.

Pratiques communautaristes et idéologies nationalistes dans la Yougoslavie socialiste Comme l'ont noté de nombreux observateurs de la Yougoslavie socialiste, celle-ci passe progressivement d'un système fédéral, relativement centralisé, à un système confédéral où l'essentiel du pouvoir revient aux républiques et provinces autonomes constitutives, et aux Ligues des Communistes qui leur correspondent ${ }^{15}$. Ce basculement est particulièrement sensible dans la période comprise entre 1966 (chute de A. Rankovic, chef des services secrets yougoslaves et partisan d'un Etat centralisé) et 1974 (adoption d'une nouvelle Constitution décentralisatrice). Le "printemps croate » de 1971, marqué par l'affrontement entre la Ligue des Communistes croate d'une part, les autres Ligues des Communistes et l'armée fédérale d'autre part, montre comment, dans le même temps, la politique des nationalités devient pour des élites politiques républicaines rivales un lieu et un vecteur privilégiés d'affrontements et de relégitimation auprès de leurs communautés nationales respectives. Les explications de cette décentralisation du système institutionnel et politique yougoslave, et de cette résurgence en son sein $\mathrm{du}$ communautarisme, sont multiples et souvent complémentaires ${ }^{16}$. Tout d'abord, l'industrialisation et l'urbanisation rapides de la Yougoslavie après 1945 se sont accompagnées de déséquilibres de deux sortes. Le premier, entre régions développées du nord (Slovénie et Croatie essentiellement) et régions sous-développées du sud, a aggravé les conflits entre des républiques et provinces autonomes aux intérêts économiques divergents. L'autre déséquilibre, entre communes urbaines insérées dans le développement économique et communes rurales marginalisées, a réalimenté les éternelles frustrations du monde paysan. De plus, les catégories de population nées de la modernisation (nouvelles élites économiques et scientifiques, population urbaine scolarisée), porteuses de nouvelles aspirations politiques et culturelles, ont elles-mêmes contesté la légitimité d'une idéologie et d'élites politiques héritées du mouvement des partisans. Cette confrontation entre nouvelles élites économiques et scientifiques et anciennes élites politiques et militaires a recoupé et réactivé d'anciennes rivalités entre communautés nationales, comme l'illustre, là encore, le "printemps croate " de 1971 puis la crise de la Ligue des Communistes de Yougoslavie entre 1986 et 1989. En Bosnie-Herzégovine, la décentralisation et la résurgence du communautarisme prennent des formes particulières. Les années 1960 y sont marquées par un rééquilibrage au détriment de la communauté serbe jusqu'alors dominante, et au profit de la communauté musulmane, reconnue comme nation constitutive de la Bosnie-Herzégovine puis de la Yougoslavie ${ }^{17}$. Surtout, alors que les autres républiques et provinces autonomes correspondent chacune à une communauté nationale spécifique, la Bosnie-Herzégovine est la seule république yougoslave à avoir trois communautés nationales constitutives (Musulmans, Serbes et Croates). Cette spécificité explique tant le rôle fondamental mais souterrain des rivalités communautaires dans la Ligue des Communistes de Bosnie-Herzégovine que celui joué par les institutions nationales extérieures à la Bosnie-Herzégovine (Académie des sciences serbe et Matica Hrvatska croate) ou les institutions religieuses (Islamska Zajednica, Communauté islamique, en premier lieu), en l'absence d'institutions communautaires spécifiques dans cette république. En 1980, le maréchal Tito, arbitre incontesté du système politique yougoslave, meurt. L'aggravation de la crise économique et l'épuisement de l'idéologie communiste suscitent une montée des 
revendications et des idéologies nationalistes, comme en témoignent dès 1981 les manifestations albanaises au Kosovo. Cette montée des nationalismes s'explique par un phénomène de "conversion nationaliste " de frustrations d'ordre économique ou politique. Ainsi, les manifestants albanais revendiquent-ils une république du Kosovo comme solution au sous-développement économique de la province. Quelques années plus tard, les manifestants serbes du Kosovo expliquent par d'hypothétiques "pressions albanaises » une émigration de nature essentiellement économique ${ }^{18}$. Cette "conversion nationaliste", encouragée par des élites politiques rivales, ne peut toutefois être réduite à une simple manipulation de leur part. Elle repose sur les pratiques et les représentations communautaires des populations elles-mêmes. De plus, comme le note S. Maliqi à propos de la crise du Kosovo, cette «conversion nationaliste" de frustrations d'ordre économique ou politique représente une "réduction étatiste de la conscience » à travers laquelle « le problème du Kosovo est réduit à un problème national (...) alors que d'autres aspects, plus importants, d'une réalité kosovar contradictoire sont mis de côté ", le problème national est lui-même réduit à " une conquête de l'Etat permettant d'introniser une bureaucratie nationale " 19. La montée des nationalismes en Yougoslavie ne peut donc être analysée sans prendre en compte le rapport ambigu à l'Etat de populations marquées par l'Empire ottoman, le système communiste et, plus spécifiquement, une Yougoslavie fédérale et autogestionnaire dans laquelle l'Etat était à la fois partout et nulle part. Au fur et à mesure que la crise yougoslave s'aggrave, ce phénomène de " conversion nationaliste " s'étend à l'ensemble des communautés nationales et des républiques. Les années 1980 sont marquées par une revalorisation des identités nationales et surtout confessionnelles, et par un rapprochement entre des élites politiques communistes et les élites religieuses ou oppositionnelles. Le "phénomène S. Milosevic " à partir de 1986, et le rôle joué par l'église orthodoxe et l'Académie des sciences serbe dans celuici, fait, dans ce contexte, figure de paradigme plutôt que d'exception ${ }^{20}$. Les différences entre républiques sont toutefois considérables. Ainsi, les Ligue des Communistes de Serbie et du Monténégro incarnent sous la direction de S. Milosevic un nationalisme agressif et autoritaire, les Ligues des Communistes de Slovénie et de Macédoine incarnent quant à elles un nationalisme modéré et réformateur. Celles de Croatie et Bosnie-Herzégovine, restées peu nationalistes mais conservatrices, seront balayées par des partis nationalistes et anticommunistes lors des élections libres de 1990. Ces différences expliquent pourquoi la Ligue des Communistes de Yougoslavie éclate lors de son XIVe Congrès en janvier 199021. Dans l'ensemble de la Yougoslavie, la logique titiste du « diviser pour régner » fait place à la logique nationaliste du « se diviser pour régner ». Dès la fin des années 1980, la Ligue des Communistes de Bosnie-Herzégovine était, du fait de sa composition pluri-ethnique, la plus stricte dans la réaffirmation du dogme titiste "d'unité et fraternité », mais aussi la plus affectée par les clientélismes, les rivalités et les règlements de compte à base communautaire. L'éclatement en août 1987 de l'affaire Agrokomerc révèle le degré de corruption et de décomposition interne alors atteint par cette Ligue. Scandale financier à l'origine, l'affaire prend rapidement une dimension politique et se solde par la chute du principal dirigeant communiste musulman H. Pozderac, protecteur de F. Abdic, directeur d'Agrokomerc et véritable «baron» de la Cazinska Krajina (région de Bihac). Dans les années suivantes, les scandales, les divergences politiques et les conflits nationaux se multiplient et se recoupent au sein de la Ligue des Communistes de Bosnie-Herzégovine. Son dernier Congrès en décembre 1989, destiné à préparer le XIVe Congrès fédéral, voit 
l'affrontement d'organisations locales de composition nationale différente, la victoire $\mathrm{du}$ courant conservateur mené par le président musulman du Comité Central $\mathrm{N}$. Durakovic et l'adoption de résolutions mitigées et obsolètes (réaffirmation du dogme titiste, rejet des projets serbe et slovène de réforme constitutionnelle, refus du pluripartisme). En mai 1990, la Ligue des Communistes de Bosnie-Herzégovine participe à une tentative de reprise du XIVe Congrès, et ne se transforme en Stranka Demokratske Promene (SDP, Parti du Changement Démocratique) qu'en septembre 1990. La légalisation tardive du pluripartisme en Bosnie-Herzégovine se double dans un premier temps de l'interdiction de toute "association fondée sur l'appartenance nationale ou religieuse, sauf dans le cadre de la loi régissant le statut juridiqu

\section{NOTES}

1. I. Andric, "Lettre de 1920", Titanic et autres cintes juifs, Belfond, 1987.

2. En 1879 , au sortir de la période ottomane, la Bosnie-Herzégovine compte $38,7 \%$ de musulmans, $42,9 \%$ d'orthodoxes (serbes) et 18,1\% de catholiques (croates). En 1991, elle compte $43,7 \%$ de Musulmans (au sens national), 31,4\% de Serbes et 17,3\% de Croates. La population juive de Bosnie-Herzégovine, forte de 11248 personnes en 1931, n'est plus que de 377 personnes en 1953.

3. Sur la période ottomane, voir R. Mantran (éd.), Histoire de l'Empire ottoman et P.Sugar, Southeastern Europe under the Ottoman rule 1354-1804, University of Washington Press, 1974.

4. Voir C. et B. Jelavitch, Balkans in transition et K. Karpat, An inquiry into the social foundations of nationalism in the Balkans, University of California Press, 1963.

5. Sur la période austro-hongroise, voir P. Sugar, The industrialisation of BosniaHercegovina 1878-1918, University of Washington Press, 1963. M. Cupic-Amrein, Die Oppposition gegen die österreichische-hungarische Herrschaft in BosnienHerzegowina, Peter Lang, 1987 ; R. Donia, Islam under the double eagle, Columbia University Press, 1981.

6. Sur les nationalismes serbe et croate et leurs courants, voir W. Behschnitt, Nationalismus bei Serben und Kroaten 1830-1914, Oldenburg, 1980 ; I. Banac, The national question in Yugoslavia : origins, history, politics, Cornell University Press, 1984.

7. Sur la vie politique dans la première Yougoslavie, voir I. Banac, op. cit., et A. Purivatra, JMO u politickom zivotu kraljevine Srba, Hrvata i Slovenaca, Svjetlost, 1974. 8. Sur ce courant, voir E. Redzic, Muslimansko automastvo i 13. SS divizija, Svjetlost, 1987.

9. Voir B. Denitch, The legitimation of a revolution, the yugoslav case, Yale University Press, 1976.

10. Voir A. Purivatra, Nacionalni i politicki razvitak Muslimana, Svjetlost, 1969.

11. Voir en particulier P. Shoup, Communism and the yugoslav national question, Columbia University Press, 1968.

12. Voir L. Cohen, The socialist pyramid. Elites and power in Yugoslavia, Mosaic, 1989. 
13. Voir J. Tomasevitch, Peasants, politics and economic change in Yugoslavia, Oxford, University Press, 1955.

14. Ainsi, Sarajevo compte en $188560,1 \%$ de musulmans, $16,9 \%$ d'orthodoxes, $12,7 \%$ de catholiques et $10,0 \%$ de juifs. En 1910, elle compte 35,6\% de musulmans, 34,5\% de catholiques, 16,3\% d'orthodoxes et $12,3 \%$ de juifs. En 1948, elle compte $36,0 \%$ de Serbes, $34,6 \%$ de Musulmans et 23,3\% de Croates. En 1991 enfin, elle compte 41,5\% de Musulmans, 27,\% de Serbes, 8,9\% de Croates et 18,7\% de Yougoslaves.

15. Sur l'évolution de la Yougoslavie socialiste, voir D. Rusinow, The yugoslav experiment, Hurst, 1977 ; S. Burg, Conflict and cohesion in socialist Yugoslavia, Princeton University Press, 1983 ; P. Ramet, Nationalism and federalism in Yugoslavia, Indiana University Press, 1984 ; J. Krulic, Histoire de la Yougoslavie, Complexe, 1993. 16. Sur la crise de la société yougoslave, voir S. Pawlovitch, Yugoslavia : the improbable survivor, Hurst, 1988 ; P. Ramet (éd.), Yugoslavia in the 80's, Westview, 1985 ; Z.Golubovic, La crise de la société yougoslave, Index, 1986 ; L. Sekelj, Struktura raspadanja Jugoslavije, Rad, 1990.

17. Sur cette promotion sociale de la communauté musulmane, voir X. Bougarel, Bosnie-Herzégovine : anatomie d'une poudrière, "Hérodote", n 67, 4e trimestre 1992. 18. Sur la crise du Kosovo, voir M. Roux, Les Albanais de Yougoslavie. Minorité nationale, territoire et développement, M.S.H., 1992 ; B. Horvat, Kosovsko pitanje, Globus, 1989.

19. S. Maliqi, Kosovo kao katalizator jugoslovenske krize in S. Gaber (éd.), KosovoSrbija-Jugoslavija, ZSMS, 1989.

20. Sur S. Milosevic, voir N. Popov, Le populisme serbe, "Les temps modernes", avril 1994.

21. Sur l'évolution divergente des différentes ligues républicaines, voir D. Sekulic, "Nationalism versus democracy : legacies of marxism" in International Journal of Politics, Culture and Society, n VI/1, automne 1992.

\section{INDEX}

Index géographique : Balkans, Bosnie-Herzégovine

Mots-clés : Etat-nation, guerre, Nationalismes, identité 